\title{
English Course Books and Language Awareness of Young Learners
}

\author{
Maria Stec \\ University of Silesia, Poland Katowice-Cieszyn
}

\begin{abstract}
The paper describes the latest approaches to English course book design with a focus on grammar that helps to develop children's language awareness. The aim is to find answers to the following questions: What are the latest tendencies in course book design for children? How is language awareness promoted in English course books for young learners? The results indicate that more and more attention is devoted to the selection of language and visual content. It is hoped that the results from the research will bring implications for early language education and enrich the process of materials construction.
\end{abstract}

\section{Introduction}

Early foreign language learning (EFLL) is generally supported as it can have a very positive effect on children in terms of language skills, positive attitudes to other languages and cultures, as well as their self-confidence [1]. The popular idea is to teach English to young learners (YL) as they learn to communicate, develop a positive attitude to English culture and become more aware of their mother tongue as well as other languages [2]. In this project, the term YL refers to children whose age ranges between six and eleven years [3].

A period of learning in primary school can be divided into two stages: early grades and subsequent grades as learners differ in terms of their holistic development, their intellectual and social maturity, ability to read and write, ability to reason logically and develop abstract thinking. The stages are reflected in teaching materials for primary school. The first stage refers to YL in 1st, 2nd and 3rd grades, who become sensitize to English and experience this language through play-like activities. The second stage refers to older learners in 4th, 5th and 6th grades, who are to experience more organized English including more systematic teaching of grammar.

The whole language approach, inductive approach and implicit grammar teaching are included in instructional materials for YL. In practice, they encounter grammatical categories in the instructions. Namely, YL encounter chunks, phrases and sentences, which are learnt in chants, rhymes, songs and stories, to express functions. Consequently, EFLL including grammar teaching, can be viewed as consciousness raising process or discovery learning through particular activities. In Ur's opinion, there is a number of aspects, which are taught to learners while they are encountering grammatical structures. Namely, YL perceive and recognize the spoken and written forms of the structure as well as comprehend the spoken and written structures in context [4]. Moreover, development of language awareness during EFLL can occur in three following stages:

1) Noticing new language structures: teachers focus YL' attention to the forms of the target language so they perceive the structure and meaning.

2) Structuring knowledge of English system: YL manipulate forms and meanings of the structures in controlled practice (for example drills).

3) Proceduralizing: YL use English fluently and communicate in the controlled context [5].

English teachers are supposed to concentrate on the receptive skills in a primary classroom as the official document - Polish Core Curriculum focuses, first of all, on the comprehension of languages in EFLL. The aims of learning modern languages involve psychological, linguistic and cultural preparation. The detailed objectives in teaching materials for YL are classified in four following points [6]:

- Learn to communicate in English.

- Develop a positive attitude to EFLL.

- Develop a positive attitude to culture.

- Raise awareness of mother tongue and English.

YL develop meta-cognitive awareness which is an umbrella term involving language, cognitive, social and cultural awareness. Teachers help YL to understand how they can learn languages through observation and comparison. Still, children by the age of 11 are not able to understand abstract rules in detail [7]. As far as language awareness is concerned the idea is to stimulate children's interest and curiosity about language [8] in order to develop understanding of the mother tongue and other languages. The process requires the implementation of meta-language to discover rules about a language, describe it, and compare them between L1 and L2 .

New approaches to teaching children have never totally replaced the previous ones and consequently this has led to an eclectic approach. The eclectic approach indicates that EFLL should be adjusted to each group of learners [9]. Then, the principles concerned with the holistic development of $\mathrm{YL}$ should be incorporated in materials [10]. The most essential skill is the translation of these principles into course book design [11]. 
There are plenty of course books on the marketfor teaching English to YL (TEYL) and their adequacy is always tested in practice. Normally, course books are viewed as the centre of any EFLL and teachers (learners) rely on them to a large extent. It is stated that materials contribute to the effective teaching [12]. To provide support in learning, they are supposed to be useful, meaningful and interesting for YL as well as suitable for their needs. To provide support in teaching, they should have clear procedures and methods of instructions. Materials should offer standard, natural and current language as well as include unbiased and recent information on the target language culture [13].

Allwright claims that learning materials rather than teaching materials are needed in education. $\mathrm{He}$ advocates learning materials with two types of guidance: the first guide for the independent language learning to establish priorities and adjust exercises for learners' personal use; the second guide is for the successful language practice, which contains hints how to exploit the language learning situation [14].

An investigation of course books may refer to two types of examination: course book assessment and course book evaluation [15]. Course book assessment refers to out-of class judgment on the appropriateness of a new book for a specific course and group of learners. Course book evaluation refers to post-use judgment on how well the selected course book has met the needs of the users, which requires the teacher's reflection on the content covered.

In this paper a major focus is on the course book assessment, which can be divided further into two stages: evaluation for selection and analysis for implementation [16]. The evaluation for selection involves decisions on one course book, which can be undertaken with the help of a checklisti. Still, this project focuses on the analysis for implementation, which refers to the overview of the selected course books. The process involves the initial reading of its organization, the analysis of its content, activities and guidelines for teaching. In the investigation of units, the content and balance of grammar, lexis, pronunciation, skills, integration and learning strategies; aims and their relevance, quantity and challenge; topics and their relevance and interest; methodology, materials and their methodology; texts and their relevance to aims, complexity, authenticity and length; support in terms of rules, explanations and guidelines are analysed [17]. Then, there are many areas to be checked before the formal acceptance of course books for education.

\section{Research Objectives}

The assumption is that children's needs and appropriate conditions (course books) are required for successful EFLL [18]. The objective is to describe the policy of teaching English to young learners (TEYL) and the latest tendencies in course book design for YL with a focus on grammatical content needed for language awareness.

\section{Research Questions}

The idea is to find the answer to 3 major questions: What is the policy of TEYL? What are the latest tendencies in course book design for YL? What do English course books offer for raising children's language awareness? Then, the project involves the following detailed questions:

1) What entry profile of YL is required in the course books?

2) What graduate profile of YL is desired in the course books?

3) What are the goals in the course books for YL?

4) What level of language is offered in the course books for YL?

5) How is the course book content organised?

6) How is the course book content sequenced?

7) What "visual content" is provided?

8) What grammatical content is provided?

a) How grammatical categories are indicated in contents?

b) How are the grammatical categories presented in course-books?

c) What grammar practice is offered in course books?

d) What grammar revision is offered in coursebooks?

9) What types of topics are presented in the course books?

10)What approaches are indicated in the course books for YL?

11) What techniques and activities are indicated in the course books for YL?

12)What guidance does the course book provide for TEYL?

13) What forms of liaison are indicated?

\section{Research Scheme}

The project involves two stages of the research. The first stage involves an investigation of European and Polish documents describing the policy of EFLL. It is based on the data obtained during my $\mathrm{PhD}$ studies.

\footnotetext{
There is a wide selection of ready-made checklists published for this type of assessment. To name a few, these are: Textbook Evaluation Ur, 1996:186); Checklist for Course Book Evaluation (cf. Byrd, Checklist (cf. Robinett, 1978:149-151 after Brown, 1994:150-151); Materials Test for Assessment (cf. Tanner and Green, 1998:120-121); Checklist for Course Book Assessment (cf. 2001:425-427); Areas for Assessment (cf. Harmer, 2003:301304); Control Questions for Course Book Assessment (cf. Komorowska, 2005:42-43).
} 
The second stage involves an analysis of the instructional materials with the help of a check-list. A course-book evaluation check-list is designed for the second stage and includes a set of thirteen questions. The questions are open plus extra remarks on teaching grammar are welcomed. The check-list is divided into eight groups of the questions including:

- Questions about YL: relate to the entry and graduate profile of children required in the course book implementation.

- Questions about goals: relate to the goals and aims in the course books for YL.

- Questions about level: relate to the level of English offered.

- Questions about contents: relate to the grammatical structures in the course-books: their selection, gradation, presentation, practice and revision).

- Questions about approaches and methods: relate to the theoretical tendencies suggested in course books for teaching grammar.

It is based on the data obtained during the review studies on English course books for the Polish Ministry of Education. Only later all the results gathered during the research are compiled together and the comparative study is recorded [19].

\section{Research procedure}

The first stage involves an investigation of Polish and European documents describing the policy of EFLL. The second stage involves an analysis of English course books for YL. The investigation is initiated by course book sample selection. Coursebooks had to fulfil two criteria [20]:

- Practical consideration: materials should be implemented in primary schools.

- Up- to- date methodology: materials should reflect the latest psychological, pedagogical and linguistic approaches.

- Needs of YL are grouped in two categories: grades 1-3, grades 4-6.

\subsection{Sample selection}

For the purpose of the investigation ten course books were selected and coded: C1, C2, C3, C4, C5 (implemented in the first stage of EFLL) and C6, C7, C8, C9 and C10 (implemented in the second stage). The process requires a precise identification of feedback and analysis of data. The results from the course book evaluation are recorded and compiled on charts. The final step is to compare the answers collected in the respective stages.

\subsection{Course of the evaluation}

For the purpose of the project a detailed list of criteria is designed. The list of criteria, which is designed on the basis of the literature ${ }^{\mathrm{ii}}$ and the author's individual experience, includes the following items:

1) Profile of YL.

2) Goals of the course books.

3) 3) Level of English language for YL.

4) Content in the course book (content selection, gradation, organisation; grammatical content).

5) Topics in the course books.

6) Approaches and methods in the course books.

7) Techniques in the course books.

8) Guidance for teachers and learners.

9) Liaison with primary education.

In terms of grammar structures, the additional criteria were designed for the project such as amount of grammar, approaches to teaching grammar, selection of structures, sequence (gradation) of structures, presentation of grammar (examples, terminology and language used), practice of grammar (context and activities), revision of grammatical categories [21].

\subsection{Interpretation of the results}

In the first stage of the research, the results indicate that the policy specifies regulations and standards for TEYL as well as provides a framework for EFLL. The standards reflect national and international importance (national priorities towards a particular language) and community support (parents and family, languages and heritage of YL' background), articulation (the language sequence for further school levels) and resources [22]. The regulations state the period of time and frequency of lessons allotted for teaching languages in primary schools.

Planning the classroom work requires decision making skills concerned with a specific school year, a course, a syllabus, a course book, a series of lessons, a lesson and topic. The classroom work is based on the teacher's knowledge and interpretation of the core curriculum, for example a new Core Curriculum Statement has been introduced in 2010 in Poland [23]. In planning resources, the teacher is responsible for the selection and assessment of course books or extra materials.

ii The literature consulted: Hutchinson and Waters, 1987:96-105;
White, 1988:48; Sheldom, 1988:243-245; Johnson,
1989:232;Alderson, 1992:25; Weir and Roberts, 1994:113-115;
Wallace, 1998:185-190; Ornstein and Hunkins, 1999:318;
Richards, 2001:231-301; Komorowska, 2005:48-50.
White, 1988:48; Sheldom, 1988:243-245; Johnson, , $1992: 25$; Weir and Roberts, 1994:113-115; Richards, 2001:231-301; Komorowska, 2005:48-50. 
In relation to the EU recommendations, teaching foreign languages to YL in Poland faces a number of challenges such as lowering the starting age for EFLL and integrating it with the school curriculum. In this context, three aspects of the Polish primary education reform have an impact on course and materials design [24]:

1. Integrated primary subjects that support the content-based instruction and cross-curricular topics in the teaching materials.

2. Descriptive evaluation and assessment including elements of learners' self-evaluation.

3. End of school test to function as a diagnostic instrument for further language education.

Teaching foreign languages in the primary context is important to children, parents, teachers and administrators. Following the Polish national policy, EFLL starts in the 1st grade of primary schools and usually involves 2 forty-five minute lessons per week. YL are taught either by a primary education teacher (a general teacher) or a foreign language teacher (a specialist subject teacher) [25]. The aim is to prepare YL for communication in English and raise their awareness of both foreign language(s) and mother tongue.

Similarly to other Member States, the five following issues are stressed in Poland: advantages coming from children's aptitude for EFLL, variety of linguistic situations and lowering of the starting age for EFLL; integration of EFLL with other subjects in the context of primary education; EFLL as the preparation for further linguistic education; teachers' linguistic and pedagogical skills for teaching YL. Primary methodology and time factor seem to be the main considerations. The majority of achievements planned will depend on the support provided by the international, national and local authorities.

In the second stage, the results from the checklist reveal the entry profile of YL. They differ in terms of holistic development, intellectual and social maturity, ability to read and write, ability to reason logically and develop abstract thinking. The two stages are reflected in English teaching materials for the first and second stage of primary education. YL in 1st, 2nd,3rd grade start learning English almost from "zero". It is assumed that they share similar characteristic features and are beginners in EFLL (or they may have been learning it for a relatively short period of time). They become sensitize to English and experience this language through games, plays, songs and rhymes. They also begin to experience the process of schooling.

Then, the graduate profile of YL after 3rd grade indicates that they should be prepared for the second stage of modern language education. The second stage refers to learners in 4th, 5th and 6th grades, who are to experience more organized process of English learning including more systematic teaching of grammar. They have already known the process of schooling.

As far as the goals are concerned, three groups of elements are identified in the course books. These are: educational goals (key competencies in the core curriculum statement for primary education), which focus on the most essential schooling skills and abilities; teaching goals (educational goals listed as non-linguistic skills) including intercultural competence of YL, development of a positive attitude to other languages and cultures, learning strategies and learning autonomy; teaching objectives (listed as linguistic skills) to be learnt by YL and defined in operational forms. A level of English offered in the investigated course books is defined generally as the elementary level or A1 in CEFR.

Content in the course books: a selection of lexis (pronunciation) is listed as words and phrases, which describe the world of YL (e.g. their personal details, names of objects in the classroom, home and school, toys, daily activities, colours, animals, fruits and vegetables, seasons, days, months) and other words associated with the topics and situations interesting for YL. A selection of functions is listed as the basic communicative functions needed for dialogues, (e.g. to greet, say goodbye, identify and present people, places, time, describe abilities and behaviours and give orders).

A selection of grammatical categories is listed and the following items are recommended:

- countable/uncountable nouns;

- determiners and pronouns;

- question forms;

- prepositions of place/time and space;

- $\quad$ adjectives; adverbs;

- conjunctions; imperatives,

- present/future/past forms of tenses and modal verbs.

The major discrepancies between the first and second stage of EFLL in terms of grammar relate to the group of nouns, verbs and numbers. A scope of nouns, a selection of tenses (plus conditional sentences or passive construction) as well as numbers are extended in the second stage of primary education in a comparison with the first stage of education. A smaller number of differences occur in other categories such as pronouns, determiners or conjunctions.

The eclectic approach is recommended in terms of procedures for the first stage of primary school. Additionally, mechanical learning of structures is highlighted including model sentences, Q-A drills, fill-in-gaps, songs, chants, puzzles, stories and correction. Grammar is not included in the assessment charts designed for children at this level. Similarly, the eclectic approach prevails in TEYL in the second stage of primary school. In particular, grammatical categories are taught through dialogues, 
drills, model sentences stories, fill-in-gaps, roleplays and games. However, both inductive and deductive approaches are suggested for learning/teaching grammar, including an analysis of rules and an introduction of terminology such as parts of speech/parts of sentences in L1 or even L2. Grammar is included in the assessment charts designed for the second stage of EFLL.

Considering the selected course-books, differences in teaching grammar and raising awareness seem to be even more clear and obvious between the first and second stage of primary education. In particular, grammatical categories as such are not indicated in contents of the course books for the 1st, 2nd and 3rd grades, which are mainly dominated by topics. Still, grammatical categories are pointed clearly in contents of the course books for the 4th, 5th and 6th grades and grouped in various sections, for example entitled "Language Focus". As a rule, the implicit and covert way of teaching grammar supports the development of language awareness in the first part of EFLL while more analytical, in/deductive approaches stimulate this process later.

To compare a range of grammatical categories, the basic structures such as imperatives are characteristic for the first part of primary school while more complex structures such as present, past, future structures, or in other words everyday English, are typical for the subsequent stage of TEYL. The most popular grammar sequence in the early stage involves the modular and storyline sequence whereas the spiral and modular in the second stage of English education.

Introduction of the grammatical categories in all selected course books follows the same pattern in all grades. Initially, structures are presented orally; later their meaning and form and finally structures are rewritten (grades 4-6). The most popular are imperatives and short sentences in the first part of primary education while Q-A sentences and dialogues are the most frequent constructions in the second stage of primary school. The grammatical terminology is not included in the course books for the first stage of EFLL whereas the course books for the second stage include more (or less) complex grammatical terms that are provided either in L2 or L1, both L1 and L2 depending on authors or tradition of the publishing house.

The most popular activities used for presenting grammar are chants, songs and stories in the first part of education while dialogues, stories and charts in the second part of education. As far as the practice of grammar is concerned, the most popular activities include fill-in-gaps, puzzles, complete sentences and games with the frequency of $2 / 3$ tasks per lesson in the 1 st, 2 nd and 3 rd grades. The most common type of activities in the 4th, 5th and 6th grades involve drills, dialogues, corrections, fill-in-gaps and multiple choices with the frequency of 2 up till 6 tasks per lesson.

Finally, a revision of grammar is not provided in the course books for the first stage of EFLL. Later, revisions are provided more and more frequently, for example after each 1, 2 or 3 units in the second stage of primary education. At this level course books also offer a summary of grammar in L1 or L2.

The content order and selection in the course books vary to a very small degree. Namely, topics always refer to the world of $\mathrm{YL}$ and their background. The most popular topics are listed as Family and Relatives, Games and Toys, Animals and Pets, Food and Drinks, Home, Health and Parts of the Body, Clothes, Shops and Money, Sports and Hobbies, School, Friends, Jobs and Skills, Everyday Objects, Time/Days/Months/Season, Weather and Everyday Plans, Places and Buildings, Holidays and Traditions, Countries, Nationalities and Travelling, Means of Communication, Directions and Means of Transport, Feelings and Opinion, Literature for YL Fairy Tales.

The content sequence in the selected course books is based usually on spiral, modular and less frequently on story-line models. The content is always organized around topics while the receptive skills are practised before the productive ones. The "visual" content varies from one book to another but often the clear and simple pictures are offered for YL in the first stage. The appropriate colour and size of the illustrations plus the interesting outline of a course book are three factors that determine the effective and successful comprehension and perception of YL in the whole periof of EFLL. The most confusing for YL are too small (or too big) elements to recognize details, e.g. to count too small flowers. Another problem is concerned with too many similar elements in one picture, which are distracting to solve the task, e.g. "abstract" and dressed up animals difficult to define for them even in the mother tongue.

As far as the approaches or methods offered in the course books are concerned, in the whole period of EFLL there are usually topic-based approach, task based approach, TPR, Communicative method, new technologies, strategy training and MI principles. A selection of techniques presented in the course books differ only to a small degree as the majority of them are discovery in nature. The most popular are songs, stories, chants, drawing and colouring tasks and projects. Instructions in the tasks are offered either in Polish or English. The less popular are instructions in two languages simultaneously. The latest course books provide descriptions of the learning process at the bottom of the page, e.g. YL describe the picture and repeat new words. It is a kind of help only for teachers and parents.

Further study concerned with English teaching materials reveals the basic set of guides for users. 
The set includes a course/exercise book, a teacher's book, a syllabus guide, flashcards and result schedules. Fairy-tales, DVD films and materials found via the Internet are recognised as extra resources. Nevertheless, a range of materials applied in primary schools varies to a considerable degree and presently teachers have a lot of materials to choose from.

Finally, considering the liaison with primary education, the selected English course books are compatible with the integrated primary education. The materials include aspects of teaching music, art, maths, biology, geography or information technology. They incorporate elements of national and international culture. The degree of liaison depends on the author's perception of child's world.

\section{Conclusions}

The following conclusions may be drawn from the research study:

1. In terms of the policy, it is obvious that TEYL is very popular in Poland presently. The situation is shaped by children's, parents' and administration's needs as well as international, national and local conditions. Each course book has to meet the requirements stated in the Core Curriculum and European recommendations for EFLL. In practice, 1 title of the course book (in three parts) is designed for the first stage of modern language education (grades 1, 2, 3) and also 1 title of the course book (in three parts) is designed for the second stage of primary school (grades 4,5 and 6) respectively. Presently, there are many course books available on the market and teachers selects them independently. The policy is to offer as many books as possible to meet various local needs of the users.

2. In terms of the tendencies in course book design for YL, the majority of them are spiral and modular in nature. Then, more attention should be devoted to the selection of content in the context of the integrated primary education. YL develop holistically and learn better the whole "picture" of the matter. The popular tendency is to teach elements of culture, both Polish and English providing topics about Easter, Christmas and e.g. Pumpkin Day or Halloween. A tendency is to offer key words (for YL to study) at the bottom of the page, which may serve as the guide of FLL for teachers, YL or parents. Another tendency is to provide a dictionary, e.g. a picture or a word form dictionary, at the end of the course book, which often is also a kind of handwriting practice as YL may trace the words. They learn English words, practise handwriting and develop their muscles of the wrist.

Moreover, language content is very important in course book design as well as "visual" content offered in English books as children develop their perception of the world and become sensitize to art and culture. They learn to recognize "beauty" in the surrounding and do not comprehend the abstract pictures. Then, the quality, selection, size of illustrations plus the outline of the course books should be the best possible.

3 . In terms of raising language awareness, it should be stated that English materials offered for older YL support it more in the second stage of EFLL. Consequently, the instructional materials follow the national Core Curriculum Statement and present two different approaches to teaching grammar, which is reflected initially in syllabuses and then in course books. It is clear that the amount of grammatical categories in the first stage of primary education is more limited in the comparison with the number of structures or patterns introduced in the second part or primary school.

In particular, there is a huge "jump" and gap between these two periods in terms of principles implemented in teaching grammar and raising language awareness of YL. Namely, presentation and practice of grammar in the 4th, 5th and 6th grades is more systematic and highlighted in the contents of course-books than in the first years of EFLL. The approach to TEYL is accuracy-based with the explanation and analysis of rules (in L1 or L2) including parts of sentences or speech. At this stage of learning YL are able to comprehend such details. Then, English teaching materials seem to support more the process of raising language awareness in the second stage of primary education.

The study is diagnostic with descriptive and evaluative functions. I hope that this project will provide useful information to course book designers and all people responsible for teaching foreign languages to $\mathrm{YL}$.

\section{References}

[1] D. Singleton, "The Critical Period Hypothesis: A coat of many colours", International Review of Applied Linguistics in Language Teaching, Mouton de Gruyter, iral, New York, vol. 43-4. 2005, pp. 269-285.

[2] J. Brewster, G. Ellis, G., Girard, "The Primary English Teacher's Guide", Penguin English Guide, Harlow, 2002, p. 5 .

[3] D. Nunan, "Teaching English to Young Learners". Anaheim, Anaheim University Press, 2010, pp. 2-3.

[4] P. Ur, "Grammar Practice Activities. A Practical Guide for Teachers", Cambridge, CUP, 1988, p. 6.

[5] R. Batstone, "Grammar", Oxford, OUP, 1994, pp. 5154.

[6] J. Brewster, G. Ellis, D. Girard, D. "The Primary English Teacher's Guide", Harlow, Penguin English Guides, 1992, pp. 5, 54. 
[7] J. Brewster, G. Ellis, D. Girard, D. "The Primary English Teacher's Guide”, Harlow, Penguin English Guides, 1992, p. 7.

[8] E. Hawkins, E. “Awareness of Language”, Cambridge, CUP, 1984, p. 4.

[9] P. Davies, E. Pearse, "Success in English Teaching", Oxford, OUP, 2000, p. 194

[10] L. Cameron, "Challenges for ELT from the Expansion in Teaching Children", ELT Journal, Year of the Young Learner, Special Edition. 2004, pp. 9-16.

[11] J. Brewster, G. Ellis, G., Girard, "The Primary English Teacher's Guide", Penguin English Guide, Harlow, 2002, pp. 5-6.

[12] R. L. Allwright, "What Do We Want Teaching Materials for?", In: ELT Journal, vol. 36/1 October, 1981, pp. 5-18.

[13] K. Kitao, S. K., Kitao, "Selecting and Developing Teaching/Learning Materials", In: The Internet TESL Journal, vol. 4/4. On: http://iteslj.org/Articles/KitaoMaterils.html (available on 16/06/04). 2004. pp. 1-5.

[14] R. L. Allwright, R. L. 1981. "What Do We Want Teaching Materials for?" In: ELT Journal, vol. 36/1 October, 1981, pp. 5-18.

[15] J. Harmer, "The Practice of English Language Teaching”. Harlow: Longman, 2003, pp. 301-307.

[16] P. Byrd, "Textbooks: Evaluation for Selection and Analysis for Implementation”. In: M. Celce-Murcia (ed.) Teaching English as a Second or Foreign Language. Boston: Heinle and Heinle, the Thomson Learning. 2001, pp. $415-428$.

[17] C. Gabrielatos, "The Coursebook as a Flexible Tool. Materials Evaluation and Adaptation", In: IATEFL Teacher Trainers and Educators SIG Newsletter, vol. 1/2004 (March), 2004, pp. 28-31.

[18] D. Nunan, "Second Language Acquisition". In: R. Carter, D. Nunan (eds.) The Cambridge Guide to Teaching English to Speakers of Other Language, CUP, Cambridge, 2001, pp. 87-92.

[19] J. C. Alderson, M. Scott, "Insiders, Outsiders and Participatory Evaluation". In: J. C. Alderson, A. Beretta (eds.) Evaluating Second Language Education. CUP: Cambridge, 1992, pp. 25-60.

[20] D. Williams, "Developing Criteria for Textbook Evaluation". In: ELT Journal, vol. 37/3, July. 1983, pp. 251-255.

[21] P. Ur, "A Course in Language Teaching", Cambridge, CUP, 1999, pp. 33.

[22] D. F. Gilzow, C. Rhodes, C. "Establishing HighQuality Foreign Language Programs in Elementary Schools". In: Perspectives on Policy and Practice. December 2000. Providence: Northeast and Island 